This is an open access article under the CC BY-NC-ND license (https://creativecommons.org/licenses/by-nc-nd/3.0/) Issue III, November 2020

ISSN 2707-9481

ISBN 978-601-323-207-2

https://doi.org/10.31643/2020.033

\author{
Sarina Rakhimova \\ Azerbaijan University of Languages, Azerbaijan \\ E-mail: az.lang.univ@edu.az
}

\title{
Compound sentences and syntaxic predicative contructions
}

\begin{abstract}
The article highlights the problem of compound sentences in the Turkic languages. Within the framework of this study, the problem of predicativity in complex sentences and the relationship of theoretical linguistics to predicative constructions used instead of a sentence member are investigated. A complex sentence, like a simple sentence, is pronounced with a single intonation, expressing a complete idea. Complex sentences describe more complex phenomena of the world around us than in simple sentences, and therefore these constructions appear as a later, higher expression of human speech. In primitive human speech, to express his feelings or other information, a person mainly used simple sentences. Later, as the connection between events became clearer, their expression in speech became more complex. Although simple sentences as components of a complex sentence, while maintaining intonation, are predicative parts of a certain syntactic construction.
\end{abstract}

Keywords: sentence, compound sentences, Turkic languages, predicativity, syntax.

Cite this article as: Rakhimova S. (2020). Slozhnyye predlozheniya i sintaksicheskiye predikativnyye konstruktsii [Compound sentences and syntaxic predicative contructions]. Challenges of Science. Issue III, p.: 210-214. (In Russian). https://doi.org/10.31643/2020.033

\author{
Сарина Рагимова \\ Азербайджанский Университет Языков, Азербайджан \\ E-mail: az.lang.univ@edu.az
}

\section{Сложные предложения и синтаксические предикативные конструкции}

Абстракт. В статье освещается проблема сложных предложений в тюркских языках. В рамках данного исследования исследуются проблема предикативности в сложных предложениях и отношение теоретической лингвистики к предикативным конструкциям, используемым вместо члена предложения. Сложное предложение, как и простое предложение, произносится единой интонацией, выражают законченную идею. В сложных предложениях описываются более сложные явления окружающего нас мира, чем в простых предложениях, и поэтому данные конструкции появляются как более позднее, более высокое выражение человеческой речи. В первобытном человеческом речи чтобы выразить свои чувства или иную информацию человек в основном использовал простые предложения. Позже, когда связь между событиями стала более 
ясной, их выражение в речи стало более сложным. Хотя простые предложения как составные части сложного предложения сохраняя интонацию являются предикативными частями определенной синтаксической конструкции.

Ключевые слова: предложение, сложноподчиненные предложения, тюркские языки, предикативность, синтаксис.

\section{Введение}

Предложение - это языковая единица, которая включает в себя фонетическую систему, словарный запас и грамматическую структуру языка. Предикативность, модальность и интонация, входящие в систему языковых компонентов, являются основными характеристиками предложения. Предикативность, модальность и интонацию закнченности следует называть общими компонентами языка и речи. Предложение, которое является основной единицей языка и речи, является ядром, главным компонентом речевой деятельности индивида. Невозможно представить какое-либо коммуникационный акт без предложения. Общение между коммуникантами может осуществится за счет разных лингвистических средств. Однако язык отличается от всех других средств общения и выступает в качестве наиболее важного из них.

Язык охватывает все сферы человеческой деятельности. Не существует такой области человеческой деятельности, где нельзя обходится без языка. Язык - бесценный инструмент для удовлетворения социальных потребностей человечества, закрепления и передачи знаний следующим поколениям. Языковые компоненты и единицы являются составляющими частями единой системы. В вершине этой системы стоит фонема, которая сама по себе не имеет никакого значения, а в конечной позиции - предложение, которое является самой большой единицей языка. Кроме того, наряду с языковыми компонентами данная система включает в себя «предикативную, модальную и завершающую интонацию, которые образуют предложение» (Qasımova, 2019). Предложение является основным средством общения в устной и письменной речи. Обмен сообщениями и информацией об окружающей среде и явлениях объективного мира вокруг нас реализуется через предложения, которые являются живой единицей связной речи.

Предложение, которое является основной и центральной единицей синтаксиса, отражает наиболее важные особенности языка. Язык отображает реальность и функцию мышления с помощью предложений. Согласно традиционному делению, предложения классифицируются как простые и сложные предложения.

\section{Эволюция сложных предложений}

Изучая исторические памятники, мы видим, что у простого предложения больше преимуществ. Хотя между некоторыми простыми предложениями в памятниках поставлено точка, если менять точку с запятой в соответствии с семантическими отношениями, то можно видеть, что данные предложения являются сложносочиненными. «По происхождению предложение следует считать самой ранней единицей языка, и оно всегда имело определенную информацию о своем развитии до настоящего времени, независимо от его структурных форм. В определенных структурных дифференциях может быть предоставлена любая информация» $(8,18)$.

В отличие от простого предложения, сложное предложение должно иметь как минимум два предикативных центра. «Сложное предложение является относительно более поздним средством выражения в культуре речи. В самом начале человек понимал и воспринимал различные аспекты существования и при выражении своих мыслей использовал простые предложения. Постепенно, по мере того, как взаимосвязи между событиями и явлениями становились ясными для человека, сложные предложения стали появлятся как средство выражения в речи. В ходе эволюции данного процесса простые предложения сначала объединялись на основе равноправия в качестве сложносочиненных предложений, и постепенно между компонентами сложных предложений стали формироваться такие взаимоотношения, как противоречие, условие, результат и т. д.» (Kazımov, 2000). 
Известный азербайджанский лингвист-исследователь по текстологии К.Абдулла пишет: «Сложное предложение - это синтаксическая конструкция, которая имеет два или более предикативных центров, единую интонацию и служит для выражения определенной идеи в целом» (Abdulla, 2012).

Если рассмотреть этапы эволюции тюркских языков, то можно увидеть, что в начальных этапах сложные предложения были сформированы путем объединения простых предложений при условии сохранения грамматической независимости этих предложений. «Исторический синтаксис сложного предложения основан на гипотезе о том, что в самые ранние периоды развития языка в качестве исходного события существовали только независимые простые предложения, затем были разработаны комбинации предложений для выражения сложных идей, а предикативные единицы предложения с равноправными частями были объединены на самой ранней стадии. Далее на основе таких предложений сформировались сложноподчиненные предложения» (Serebrennikov; Haciyeva, 2002).

Развитие сложного, в особенности, сложносочиненного предложения в тюркских языках наблюдалось еще VII веке. В поздних этапах языкового развития, т.е. ближе к XIII в. мы можем наблюдать развитие сложноподчиненного и сложносочиненного предложений на равных уровнях. В XVI в. различительные границы и черты между этими сложными предложениями в тюркских языках стали более четкими.

\section{Сложные предложения и предикативные конструкции}

В составные части сложного предложения утеряв свою предикативность могут превратить его в простое предложение. Значит, каждая составляющая сложного предложения имеет свою собственную предикативность.

Авторы, упоминающие о трансформации сложноподчиненных предложений в простые предложения, пришли к выводу, что при преобразовании первый компонент конструкции редуцируется, т.е. сокращается. Ф.А.Джалилов поддерживая данную позицию указывает три основных причин сокращения такого рода: 1 . В связи с контекстом и ситуацией в первой части предложении частично утрачивается семантическая значимость; 2. Превосходства модальных оттенков; 3. Утрата коммуникативных особенностей предикативной конструкции. Ф.А.Джалилов также отмечает, что при трансформации сложноподчиненных предложений формируются трансформы - маленькие языковые единицы. По мнению автора, сформированные трансформы могут функционировать как промежуточные слова, идиомы, фразеологизмы, предикатами и членами предложения (Джалилов, 1979).

В последние годы неоднозначное отношение к идее о том, что предложение является несамостоятельной языковой единицей, связано с развитием текстовой лингвистики. «... чтобы обосновать изучение текста в качестве синтаксической категории как языковая единица, необходимо доказать независимость предложения как речевая единица» (Abdullayev; Məmmədov, 2012). Однако, на наш взгляд, изучение текста как языковой единицы не должно заслонять идею независимости предложения: идея о том, что текст является макроединицей языка, была единодушно принята всеми лингвистами.

Учитывая вышесказанное, процесс перехода от простого предложения к сложному можно комментировать таким образом: первоначально простые предложения объединяясь на основе равноправия сформировали сложносочиненных предложений, а относительно позже, когда стали понятны причинно-следственные связи между событиями, возникли сложноподчиненные предложения. Когда люди используют простые предложения, они просто выражают отдельные мысли и события и не связывают их друг с другом. Однако в сложном предложении факты и события прочно связываются между собой. Составные части сложного предложения, то есть каждый его компонент, подобен простому предложению. Как и в простом предложении, каждый компонент сложного предложения состоит из основных и дополнительных членов, образуется в форме односоставного или двусоставного предложения. Его компоненты взаимосвязаны синтаксическими узами. Но надо отметить, что компонентов сложного предложения нельзя считать действительно независимыми простыми предложениями. Потому что все компоненты сложного предложения образуя единое целое объединяются по значению и интонации. Если сложное предложение разбить на простые предложения, прежнее значение и интонация будет утрачено. Отдельные компоненты составного предложения «простым предложением» можно называть только условно. Так как мы хорошо знаем структурные особенности простого предложения и на этой основе можем детально 
проанализировать сложное предложения. Здесь один из компонентов грамматически независим, а другой ему подчинен. Следовательно, изменение расположения компонентов вызывает семантическое изменение тоже.

История развития составных предложений в языке также считается очень древним и долгим процессом. Даже в Орхоно-Енисейских памятниках встречаются сложные формы предложений. X. Мирзазаде в своих исследованиях указывал следующие исторические причины объединения придаточного предложения с главным предложением: «1. Придаточное предложение используется вместо любой части предложения, отсутствующей в основном предложении, заменяя его. 2. Несмотря на то, что придаточное предложение формально полностью свободна, оно дополняет идею, выраженную в основном предложении (Mirzəzadə, 1990). Значит, придаточное предложение используется вместо пропущенного члена главного предложения. Утраченный член предложения сохраняя предикативность превращается в придаточное предложение. Наряду с другими связующими средствами в организации сложного предложения синтаксическая структура также играет важную роль: компоненты (главное и придаточное предложения) структурно совместимы, то есть, порядок членов первого компонента (придаточного предложения) соответствует порядку членов второго компонента (главного предложения).

Известно, что сложноподчиненное предложение проявляется в таких структурных типах, как «главное предложение + придаточное предложение» и «придаточное предложение + главное предложение». Формирование актуализации между компонентами этих предложений является одним из основных вопросов. Большинство лингвистов считают, что постпозитивное придаточное предложение - это рема сложного предложения. К.Абдуллаев заявляет, что «... вопрос становления сказуемого ремой в некоторых сложных предложениях широкого типа является несколько спорным вопросом, потому что в этом случае позицию перед сказуемым может занят любой член предложения. Данную позицию мы также считаем актуализированной позицией. Разговор о ремализации в двух позициях в составе одного предложении в принципе может открыть совершенно новую страницу в процессе актуализации, то есть в процессе живой речи» (Abdullayev, 2016).

Опираясь на взгляды В.В.Виноградова, К.Абдулла дальше пишет так: «Всложный предложениях широкого типа актуальное членение может проявляться посредством простых предложений. Как видно, при применении актуального членения к сложным предложениям структурные границы фактических компонентов актуализации расширяются, и тема и рема выражаются в отдельных предложениях» (Abdullayev; Məmmədov, 2012). В процессе актуального членения иногда случается так, что целое предложение актуализируясь превращается в рему.

Естественно, что сложноподчиненное предложение имеет предикативность. Его составные части по отдельность тоже являются предикативными конструкциями. «Предикативность возникает из-за расположения слов в определенном порядке и их связи с определенными грамматическими методами, которые включают категории модальность, время и лица глагола (Abdullayev; Seyidov, 1972). Их также называют предикатами. «Предикативность гармонирует и действует вместе с интонацией. Когда простое предложение становится частью сложного предложения, оно теряет свою интонацию законченности и следует общей интонации сложного предложения. Придаточное предложение отличается от простого предложения, потому что в предложении, которое становится придаточным, нет законченности смысла и интонации. Такое предложение имеет только предикативность, который составляет его основу» (Баскаков, 1984).

\section{Заключение}

В предложении подлежащее часто выражает тему, которая описывает данные о событий или явлений, а рема предложения, признаки и особенности «нового» подлежащего, которые реализуются за счет сказуемого: любое простое выражение (предложение) в определении предикатов можно разделить на две части: подлежащее и сказуемое.

При выражении определенной ситуации, то есть в предложении, сказуемое и подлежащее взаимно обусловлены и являются логически-семантически равноправными по отношению друг к другу. Другими словами, в конкретном предложении подлежащее подразумевает появление сказуемого, и наоборот: сказуемое обуславливает появление подлежащего в рамках предложения.

Данный тандем можно наблюдать и на основе сложных предложениях, описывая придаточное и главное предложение. Данная закономерность в сложных предложениях распространяется по всей структуре и получается, что как придаточное предложение обуславливает реализацию главного предложения, так и главное предложение является основой для придаточного предложения. 
Ссылка на данную статью: Рагимова С. (2020) Сложные предложения и синтаксические предикативные конструкции. Материалы Международной практической интернетконференции «Актуальные проблемы науки» [Challenges of Science]. Выпуск III, стр. 210214. https://doi.org/10.31643/2020.033

\section{Литературы}

[1] Abdulla, K. (2012) Azərbaycan dilində mürəkkəb sintaktik bütövlər. Dərs vəsaiti. Bakı (на азербайджанском языке).

[2] Abdullayev, Ә. Z. Seyidov, Y. М. Həsənov, A. Q. (1972) Müasir Azərbaycan dili. Bak1: Маarif (на азербайджанском языке).

[3] Abdullayev, K. (2016) Azərbaycan dili sintaksisinin nəzəri problemləri. Bakı: Маarif (на азербайджанском языке).

[4] Abdullayev, K., Məmmədov, A., Musayev, M. və b. (2012) Azərbaycan dilində mürəkkəb sintaktik bütövlər. Bakı: BSU (на азербайджанском языке).

[5] Abdullayeva, X. (2016) Cümlə üzvləri və mürəkkəb cümlə komponentləri sırasının nəzəri əsasları (XIII-XIV əsrlər Azərbaycan ədəbi dili materialları əsasında). Fil.ü.f.d. avtoref. Bakı (на азербайджанском языке).

[6] Kazımov, Q. (2000) Müasir Azərbaycan dili. Bak1 (на азербайджанском языке).

[7] Mirzəzadə, Н. (1990) Azərbaycan dilinin tarixi qrammatikası. Bak1 (на азербайджанском языке).

[8] Müzəffəroğlu, T. (2002) Azərbaycan dilində mürəkkəb cümlənin struktur semantikası. Bakı (на азербайджанском языке).

[9] Qasımova, S. (2019) Dil və nitq komponentlərinin paralelizmi // Filologiya məsələləri, № 15, s. 161-165 (на азербайджанском языке).

[10] Serebrennikov, B. A. Hacıyeva N. Z. (2002) Türk dillərinin müqayisəli tarixi qrammatikası. Bakı: Səda, (на азербайджанском языке).

[11] Баскаков, А. Н. (1984) Предложение в современном турецком языке Москва: Наука (на русском языке).

[12] Джалилов, Ф. А. (1979) Бессоюзные сложноподчиненные предложения в азербайджанском языке. АКД. Баку, (на русском языке).

\section{References}

[1] Abdulla, K. (2012) Azərbaycan dilində mürəkkəb sintaktik bütövlər. Dərs vəsaiti [Complex syntactic units in the Azerbaijani language. Textbook]. Bakı (in Azerbaijani).

[2] Abdullayev, Ә. Z. Seyidov, Y. M. Həsnov, A. Q. (1972) Müasir Azərbaycan dili [Modern Azerbaijani language]. Bak1: Maarif (in Azerbaijani).

[3] Abdullayev, K. (2016) Azərbaycan dili sintaksisinin nəzəri problemləri [Theoretical problems of Azerbaijani language syntax]. Bak1: Maarif (in Azerbaijani).

[4] Abdullayev, K., Məmmədov, A., Musayev, M. və b. (2012) Azərbaycan dilində mürəkkəb sintaktik bütövlər [Complex syntactic units in the Azerbaijani language]. Bak1: BSU (in Azerbaijani).

[5] Abdullayeva, X. (2016) Cümlə üzvləri və mürəkkəb cümlə komponentləri sırasının nəzəri əsasları (XIII-XIV əsrlər Azərbaycan ədəbi dəbi dili materialları). Fil.ü.f.d. avtoref [Theoretical bases of sentence members and sequence of complex sentence components (on the basis of materials of the Azerbaijani literary language of XIII-XIV centuries). Ph.D. avtoref]. Bak1 (in Azerbaijani).

[6] Kazımov, Q. (2000) Müasir Azərbaycan dili [Modern Azerbaijani language]. Bakı (in Azerbaijani).

[7] Mirzəzadə, H. (1990) Azərbaycan dilinin tarixi qrammatikas1 [Historical grammar of the Azerbaijani language]. Bak1 (in Azerbaijani).

[8] Müzəffəroğlu, T. (2002) Azərbaycan dilində mürəkkəb cümlənin struktur semantikası [Structural semantics of complex sentences in the Azerbaijani language]. Bak1 (in Azerbaijani).

[9] Qasımova, S. (2019) Dil və nitq komponentlərinin paralelizmi [Parallelism of language and speech components] // Filologiya məsələləri, no. 15, s. 161-165 (in Azerbaijani).

[10] Serebrennikov, B. A. Hacıyeva N. Z. (2002) Türk dillərinin müqayisəli tarixi qrammatikası [Comparative historical grammar of Turkish languages]. Bakı: Səda, (in Azerbaijani).

[11] Baskakov, A. N. (1984) Predlozheniye v sovremennom turetskom yazyke Moskva: Nauka [Proposition in modern Turkish Moscow: Science]. (in Russian).

[12] Jalilov, FA (1979) Bessoyuznyye slozhnopodchinennyye predlozheniya v azerbaydzhanskom yazyke [Unionless complex sentences in the Azerbaijani language]. AKD. Baku, (in Russian). 